\title{
Vitamin D deficiency in pregnancy may affect fetal thymus development
}

\author{
Esra Bahar Gur ${ }^{1}$, Mehmet Serkan Gur², Ozlem Ince ${ }^{3}$, Esin Kasap ${ }^{4}$, Mine Genc ${ }^{4}$, Sumeyra Tatar ${ }^{4}$, \\ Sultan Bugday4, Guluzar Arzu Turan ${ }^{4}$, Serkan Guclu ${ }^{4}$ \\ ${ }^{1}$ Department of Obstetrics and Gynecology, Faculty of Medicine, Katip Celebi University, İmir, Turkey \\ ${ }^{2}$ Department of Obstetrics and Radiology, Faculty of Medicine, Katip Celebi University, Izmir, Turkey \\ ${ }^{3}$ Department of Obstetrics and Radiology, Faculty of Medicine, Sifa University, Izmir, Turkey \\ ${ }^{4}$ Department of Obstetrics and Gynecology, Faculty of Medicine, Sifa University, Izmir, Turkey
}

\begin{abstract}
Objectives: The aim of our study was to evaluate the association of vitamin D deficiency (VDD) during pregnancy with thymus size in full-term fetuses.

Material and methods: In this prospective study, we evaluated mid-pregnancy serum 25 -hydroxyvitamin $\mathrm{D}_{3}\left(25(\mathrm{OH}) \mathrm{D}_{3}\right)$ concentrations. The fetal thymus size was measured by ultrasound in the third trimester. Neonatal $25(\mathrm{OH}) \mathrm{D}_{3}$ levels were evaluated by umbilical cord blood sampling. Correlation of maternal and neonatal vitamin $\mathrm{D}$ levels and association between thymus size and both, maternal and neonatal vitamin D concentrations were investigated.

Results: Serum $25(\mathrm{OH}) \mathrm{D}_{3}$ concentrations were within the normal range in $48(29.8 \%)$ mothers and $10(13.1 \%)$ newborns. A strong correlation between mid-pregnancy maternal and neonatal $25(\mathrm{OH}) \mathrm{D}_{3}$ concentration $(r=0.8, p<0.001)$ was found. A significant linear correlation was observed between both, maternal and neonatal $25(\mathrm{OH}) \mathrm{D}_{3}$ concentrations and thymus perimeter length $(r=0.45, p=0.04$ and $r=0.43, p<0.01$, respectively). Both, maternal and fetal VDDs were associated with decreased thymus perimeter $(p=0.04, p=0.03)$.

Conclusions: Vitamin D deficiency during pregnancy may be associated with smaller fetal thymus. Our data suggest that VDD in pregnancy may lead to systemic inflammatory response in the fetus.
\end{abstract}

Key words: pregnancy, vitamin D deficiency, fetal thymus size

\section{INTRODUCTION}

Recent studies have shown that, beyond its role in bone metabolism, calcium and phosphorus homeostasis, vitamin D exerts profound effects in the immune system [1,2]. Studies in both, animal models and in humans have demonstrated that vitamin D deficiency (VDD) contributes to the exacerbation of both, infectious and autoimmune diseases through dysfunctional regulatory T cells $[3,4]$. The function of regulatory T cells in inflammatory diseases of the neonatal and early childhood period (e.g. allergy to cow's milk, atopic eczema, asthma, and wheezing) is closely related to VDD during pregnancy $[5,6]$. Umbilical cord T-cell receptors, which are direct indicators of T-Lymphocyte synthesis and, consequently, thymic output, are negatively correlated with vitamin D levels [7]. As a result, a hypothesis has been advanced that the season in which a baby was born may influence autoimmune and atopic disorder risk in later life. Regardless, the underlying mechanism of the association between vitamin $\mathrm{D}$ and the development of the fetal immune system remains unclear.

The thymus is the primary site of T cell differentiation in early life. This maturation process is specific to the fetal period, but antigenic and environmental changes during that time may affect the programming of the immune system [8]. Moreover, the thymus has been shown to actively respond to systemic fetal inflammation during the intrauterine period $[9,10]$. This non-specific anti-inflammatory response may be triggered by endogenous corticosteroids, systemic inflammatory mediators, and deficiency in 
the intake of proteins, minerals or vitamins [11-13]. Fetal thymus size may be a good marker of fetal systemic inflammatory response [14, 15]. Recent studies have revealed fetal thymus size to be positively correlated with the umbilical cord C-reactive protein (CRP) levels in cases with preterm premature membrane rupture (PPROM) and a strong predictor of neonatal sepsis. Additionally, it is suggested that thymus size is smaller in fetuses of preeclamptic mothers as compared to healthy controls, independently of coexisting SGA status and antenatal steroid use [16-18].

In our study, we evaluated the correlation between both, mid-pregnancy maternal and neonatal 25-hydroxyvitamin $\mathrm{D}_{3}\left(25(\mathrm{OH}) \mathrm{D}_{3}\right)$ concentration and fetal thymus size. We hypothesized that VDD during pregnancy might alter the immune system by affecting thymic development. Furthermore, restricted fetal thymus size is an accepted indicator of the systemic inflammatory response and VDD during pregnancy may cause fetal systemic inflammatory response.

\section{MATERIAL AND METHODS Study design}

The study design was reviewed and approved by the Local Ethics Committee. All study subjects provided written consent according to the procedures recommended by the 1975 Declaration of Helsinki Declaration (revised in Tokyo 2004). All study data were collected from September 2013 to March 2014. During the study period, there were 142 vaginal and 204 cesarean section deliveries in our clinic. After obtaining informed consent, healthy volunteers between 24 and 28 weeks of pregnancy attending routine antenatal examination were recruited for the study. Exclusion criteria were: intrauterine growth retardation, fetal anomaly, multi-fetal pregnancy, maternal hypertension, chronic liver or renal disease, gastrointestinal disease, rheumatic disease, current tobacco use, or any ongoing chronic medical therapies. The daily dose of $400 \mathrm{IU}$ vitamin D supplements was recommended to all pregnant women.

We hypothesized that if vitamin D deficiency during pregnancy leads to a low-level chronic inflammatory response at fetal thymus unlike pre-eclampsia or chorioamnionitis, the evaluation of a relationship between vitamin D level in mid-pregnancy and fetal thymus size in late pregnancy may be a more appropriate approach. Therefore, maternal blood samples for the measurement of $25(\mathrm{OH}) \mathrm{D}_{3}$ level were collected between 20-28 weeks of gestation and fetal thymus measurement was performed at 37-40 weeks of gestation. The study population included 204 pregnant women. Forty-two pregnant women were excluded in accordance to the exclusion criteria in the first step. A total of 162 pregnant women who met the inclusion criteria were enrolled in the study. Pregnant women were followed up until delivery. UI- trasound measurement of fetal thymus size was performed during 37-40 weeks of gestation. The ultrasound image quality was judged to be poor in 44 patients who, together with 20 patients who were diagnosed with pre-eclampsia, gestational diabetes, PPROM or preterm labor, as well as 20 pregnant women who were missing at monitoring, were excluded from the study in the second step. Finally, cord blood samples were taken from 76 neonates at delivery. Figure 1 represents a flow chart of the study design.

\section{Measurement of fetal thymus}

A high resolution ultrasound device (Siemens; Acuson Anteres, Mountain View, CA 94043, USA) was used to perform all ultrasound measurements by two experienced radiologists with extensive qualifications in obstetric ultrasonography.

The fetal thymus was imaged in transverse at the point of the upper mediastinum adjacent to the three large cardiac vessels. The homogeneous structure within the anterior mediastinum was identified as the thymus (Figure $2 \mathrm{~A}$ ). Maximum transverse thymic diameter was defined as the diameter at the point perpendicular to the line connecting the spine and sternum and the complete perimeter was measured in the same plane (Figure 2B). Poor image quality was considered an exclusion criterion. An image was identified as poor quality under the following conditions: inability to identify the sternum and the spine, presence of multiple ribs on either side of the thorax, indicating obliquity, inability to identify the transverse thymic border [18].

A pair of observers, blinded to patient data as well as the assessment of the other observer, examined 40 out of 150 patients enrolled in the study to assess inter-observer reliability. Ultrasonic thymic perimeter and thymus/thorax diameter intra-observer reproducibility were $1.5-2.0 \%$ and $1.8-3.2 \%$, respectively.

\section{Sample collection}

Serum $25(\mathrm{OH}) \mathrm{D}_{3}$ is a marker of both, dietary vitamin $\mathrm{D}$ intake and cutaneous synthesis of vitamin $\mathrm{D}$. The normal range of serum $25(\mathrm{OH}) \mathrm{D}_{3}$ in pregnant women has not been determined. Based on previous studies in non-pregnant women, VDD was defined as $25(\mathrm{OH}) \mathrm{D}_{3} \leq 20 \mathrm{ng} / \mathrm{mL}$ $(50 \mathrm{nmol} / \mathrm{L})$. Mild vitamin D deficiency was defined as serum $25(\mathrm{OH}) \mathrm{D}_{3}$ concentration of $10-20 \mathrm{ng} / \mathrm{mL}$ ( $\left.25-50 \mathrm{nmol} / \mathrm{L}\right)$, whereas severe vitamin $D$ deficiency was defined as serum $25(\mathrm{OH}) \mathrm{D}_{3}$ concentration of $\leq 10 \mathrm{ng} / \mathrm{mL}$ ( $\leq 25 \mathrm{nmol} / \mathrm{L}$ ).

Maternal blood samples were collected within 20-28 weeks of gestation and neonatal blood was collected from the umbilical cord after delivery and clamping. Serum was separated from whole blood and stored at $-30^{\circ} \mathrm{C}$ until analyzed. Isotope dilution liquid chromatography-tandem mass spectrometry (LC-MS/MS) was used to measure 


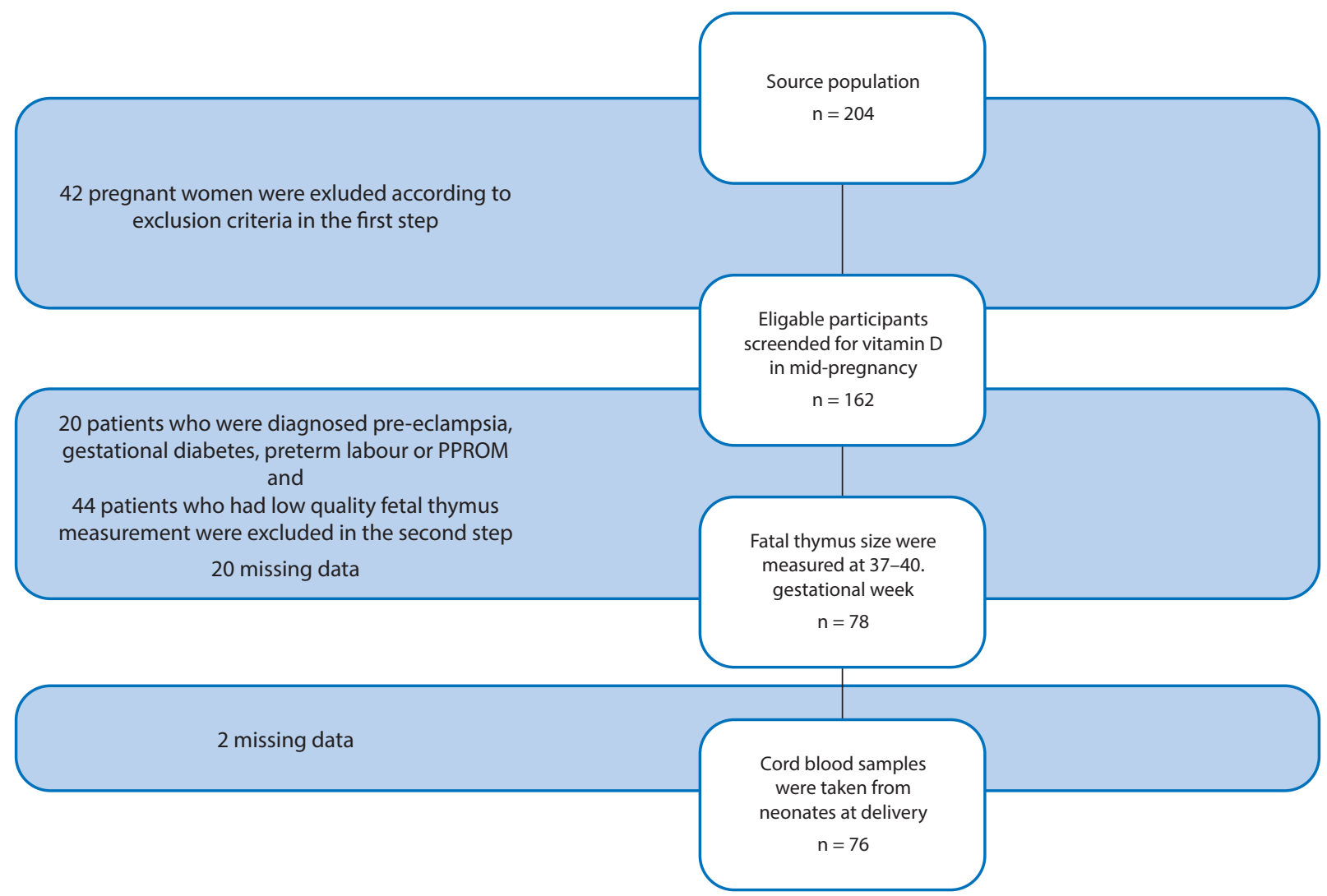

Figure 1. Flow chart of the study design. PPROM - preterm premature membrane rupture

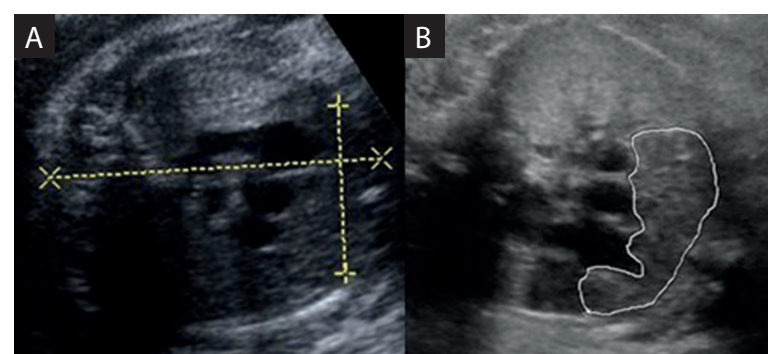

Figure 2. Sonogram of the thymus at the level of the 3-vessel view within the fetal thorax. A. Thymic-thoracic ratio. Tymus diameter was measured as its greatest width perpendicular to a line connecting the spine and sternum. B. Thymic perimeter

25(OH) $D_{3}$ concentration. The NIST SRM 972 (Chromsystems, $\mathrm{DE})$ calibrators were used.

BMI [weight $(\mathrm{kg}) /$ height $\left.(\mathrm{m})^{2}\right]$ was calculated by measuring the height and the body weight at maternal vitamin $D$ sampling.

\section{Statistical analysis}

SPSS (15.0) for Windows (SPSS Inc., Chicago, IL, USA) was used for all statistical analyses. The ANOVA test was used to test for differences within the groups. Factors associated with VDD were evaluated using multiple linear regression. The Pearson's correlation test was used to evaluate the relation- ship between thymus perimeter and diameter, as well as maternal and neonatal $25(\mathrm{OH}) \mathrm{D}_{3}$ concentrations. Differences in thymus perimeter according to cord blood $25(\mathrm{OH}) \mathrm{D}_{3}$ concentration were evaluated using ANOVA.The $p$-value of 0.05 was established as the threshold of statistical significance.

\section{RESULTS}

Mean age, BMI, and week of pregnancy were $29.5 \pm 4.3$ years, $28.8 \pm 2.6$, and $38.7 \pm 0.9$ weeks, respectively. Average maternal serum $25(\mathrm{OH}) \mathrm{D}_{3}$ concentration was $15.06 \pm 6.9 \mathrm{ng} / \mathrm{mL}$ and mean umbilical cord serum $25(\mathrm{OH}) \mathrm{D}_{3}$ concentration was $12.32 \pm 4.8 \mathrm{ng} / \mathrm{mL}$. A total of 48 mothers $(29.8 \%)$ and 10 newborns $(13.1 \%)$ had serum $25(\mathrm{OH}) \mathrm{D}_{3}$ concentrations within the normal range. Fifty-seven mothers (35.1\%) and 26 (34.2\%) newborns had mild vitamin D deficiency, whereas 57 (35.1\%) mothers and 40 (52.6\%) newborns had severe vitamin D deficiency. The basic characteristics of the study group and the $25(\mathrm{OH}) \mathrm{D}_{3}$ results are summarized in Table 1.

A strong statistical correlation between umbilical cord serum 25(OH)D3 concentration and maternal serum $25(\mathrm{OH})$ D3 concentration ( $r=0.8, p<0.001$ ) was found (Figure 3 ).

Measurements of the fetal thymus perimeter were significantly correlated with the thymic-thoracic ratio $(r=0.4$, $\mathrm{p}<0.01)$. 
Table 1. General characteristics and vitamin D status of the mothers and newborns in the study

\begin{tabular}{|c|c|c|}
\hline & & Mean $( \pm$ SD) \\
\hline Age (years) & & $29.5 \pm 4.3$ \\
\hline Mean gestational week (maternal vitamin D sampling) & & $25 \pm 0.5$ \\
\hline Mean gestational week (thymus measurement) & & $38.7 \pm 0.9$ \\
\hline \multirow[t]{2}{*}{ BMI } & & $28.8 \pm 2.6$ \\
\hline & $\begin{array}{l}\text { Mothers } \\
\mathrm{n}=162\end{array}$ & $\begin{array}{c}\text { Newborns } \\
n=76\end{array}$ \\
\hline Severe deficiency $(\leq 10 \mathrm{ng} / \mathrm{mL})(\mathrm{n}, \%)$ & $57,35.1$ & $40,52.6$ \\
\hline Mild deficiency $(10-20 \mathrm{ng} / \mathrm{mL})(\mathrm{n}, \%)$ & $57,35.1$ & $26,34.2$ \\
\hline Normal level ( $\geq 20 \mathrm{ng} / \mathrm{mL})(n, \%)$ & $48,29.8$ & $10,13.1$ \\
\hline Average level \pm SD $(\mathrm{ng} / \mathrm{mL})$ & $15.06 \pm 6.9$ & $12.32 \pm 4.8$ \\
\hline
\end{tabular}

$\mathrm{SD}$ - standard deviation, $\mathrm{BMI}$ - body mass index

Table 2. The relationship thymus perimeter with 25(OH)D3 concentrations in both maternal serum at mid-pregnancy and umbilical cord serum at delivery

\begin{tabular}{|c|c|c|c|c|c|}
\hline & Thymus perimeter & $\mathbf{p}$ & & $\begin{array}{l}\text { Thymus } \\
\text { perimeter }\end{array}$ & $\mathbf{p}$ \\
\hline $\begin{array}{l}\text { Severe deficiency, umbilical cord } \\
(\leq 10 \mathrm{ng} / \mathrm{mL}, \mathrm{n}=40)\end{array}$ & $76.9^{b}$ & \multirow{3}{*}{0.03} & $\begin{array}{l}\text { Severe deficiency, maternal serum } \\
(\leq 10 \mathrm{ng} / \mathrm{mL}, \mathrm{n}=29)\end{array}$ & $78.3^{\mathrm{a}}$ & \multirow{3}{*}{0.04} \\
\hline $\begin{array}{l}\text { Mild deficiency umbilical cord } \\
(10-20 \mathrm{ng} / \mathrm{mL}, \mathrm{n}=26)\end{array}$ & $83.7^{b}$ & & $\begin{array}{l}\text { Mild deficiency maternal serum } \\
(10-20 \mathrm{ng} / \mathrm{mL}, \mathrm{n}=26)\end{array}$ & $85.1^{\mathrm{b}}$ & \\
\hline $\begin{array}{l}\text { Normal level, umbilical cord } \\
(\geq 20 \mathrm{ng} / \mathrm{mL}, \mathrm{n}=10)\end{array}$ & $94^{\mathrm{a}}$ & & $\begin{array}{l}\text { Normal level, maternal serum } \\
(\geq 20 \mathrm{ng} / \mathrm{mL}, \mathrm{n}=19)\end{array}$ & $92.9^{c}$ & \\
\hline
\end{tabular}

$\mathrm{p}<0.05$ statistical significance

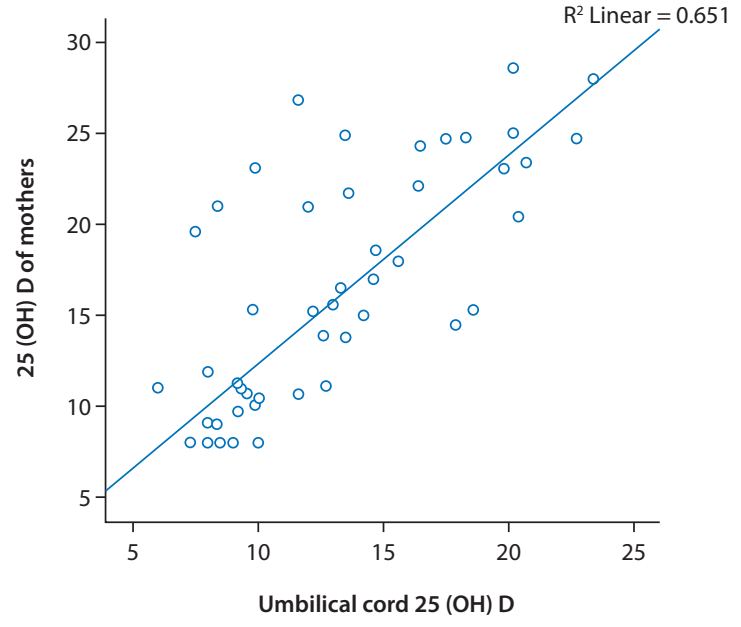

Figure 3. The relationship between serum $25(\mathrm{OH}) \mathrm{D}_{3}$ concentrations of mothers and in umbilical cord serum at delivery (Pearson Correlation coefficient $=0.8, p<0.01$ )

A statistically significant linear correlation between both, maternal serum and umbilical cord $25(\mathrm{OH}) \mathrm{D}_{3}$ concentration and thymus perimeter was observed $(r=0.45$, $p=0.04$ and $r=0.43, p<0.01$, respectively) (Figure 4).

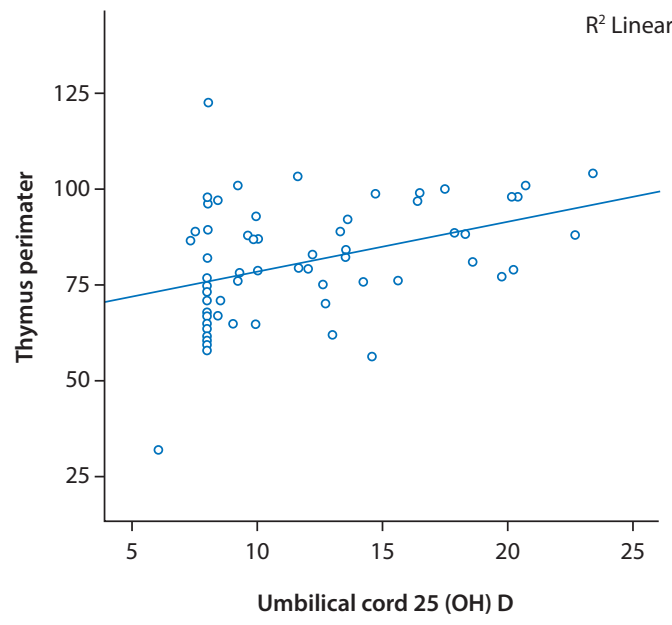

Figure 4. The relationship between thymus perimeter and $25(\mathrm{OH}) \mathrm{D}_{3}$ concentrations in umbilical cord serum at delivery (Pearson Correlation coefficient $=0.4, p<0.01$ )

Thymus perimeter differed significantly with regard to the level of both, maternal and fetal VDD $(\leq 10,10-20$ and $\geq 20 \mathrm{ng} / \mathrm{mL})(\mathrm{p}=0.04, \mathrm{p}=0.03)$ (Table 2). 


\section{DISCUSSION}

In this prospective study, we investigated the correlation between both, mid-pregnancy maternal and neonatal vitamin D levels and fetal thymus size. We found a statistically significant correlation between vitamin $D$ level and thymus perimeter $(r=0.45, p=0.04$ and $r=0.43, p<0.01$, respectively). Moreover, both maternal and neonatal VDD levels were associated with decreased thymus perimeter $(p=0.04, p=0.03)$. To the best of our knowledge, this has been the first study to evaluate the effect of VDD on thymus size in humans. The relationship between vitamin D and thymus has been investigated in two animal studies and their results are conflicting. Harvey et al., revealed that pregnant rats with VDD exhibit increased growth of central but not peripheral immune organs of the fetal thymus and leukocytes obtained from these fetuses demonstrated a pro-inflammatory phenotype [19]. These researches suggested that vitamin D may suppress growth hormone at the cellular level and an increase in fetal thymus weight might be associated with increased expression of insulin-like growth factor II (IGF-II). In a study conducted by Yurdakök et al., rats with VDD were not different from healthy controls in terms of thymus weight and histology [20].

Growing evidence shows increased inflammatory processes in patients with low vitamin D status, but little is known about this relationship during pregnancy [21, 22]. A recent study revealed that early pregnancy vitamin $D$ status is associated with some inflammatory biomarkers in mid-pregnancy [23]. In a recent animal study, researchers showed that maternal VDD leads to aberrant inflammatory responses in the fetus [24]. Preeclampsia is the most extreme point of systemic inflammatory response and offers a good opportunity to assess the inflammatory process in pregnancy. Two recent studies have demonstrated that second trimester thymus size in preeclamptic pregnant women is smaller than in healthy controls $[18,25]$. The researchers claimed that preeclampsia triggers an acute-phase reaction in the fetus, leading to activation of the hypothalamo-pituitary-adrenal (HPA) axis and cortisol release. Endogenous cortisol subsequently binds to its receptor in cortical thymocytes and induces apoptosis and thymic involution. Interestingly, some resent studies found that maternal vitamin D deficiency was associated with severe preeclampsia [26, 27]. Similarly, decreased thymus size is observed more frequently in cases of chorioamnionitis and thymus size is more sensitive than CRP in predicting histological chorioamnionitis [28]. Unlike in animal studies, we found a thymic involution in pregnant women with vitamin D deficiency. The inflammatory process which occurs as a result of VDD may have led to a reduction in the thymus size.

Recent studies have revealed that maternal and fetal VDD is common throughout the world [29, 30]. In our study, we observed normal $25(\mathrm{OH}) \mathrm{D}_{3}$ serum concentrations in 48 mothers (29.8\%) and 10 neonates (12.1\%). Fetal vitamin D is supplied by the mother and umbilical cord vitamin D levels are correlated with maternal vitamin D levels [31]. Similarly, we observed a positive correlation between cord blood and mid-pregnancy maternal vitamin $D$ levels $(r=0.8, p<0.01)$. The high prevalence of vitamin $D$ deficiency during pregnancy increases the importance of studies investigating the effect of vitamin D on fetal programming. Recent studies have implicated that vitamin D may have an important, multifaceted role in the development of fetal lungs, brain, and bone $[5,8,32]$. Similarly, the results of our study suggested that VDD during pregnancy can affect fetal programming of thymus.

Ultrasound image quality has dramatically increased, and assessment of thymus size has become feasible in most human pregnancies. In a study comparing ultrasonography with magnetic resonance (MR), ultrasonographic evaluation was found to have similar sensitivity to MR [33]. Ultrasonic measurements of fetal diameter are closely correlated with measurements of thymic volume obtained during autopsy [34]. The fetal thymus was imaged in transverse at the point of the upper mediastinum adjacent to the three large cardiac vessels. This image is relatively easy to obtain during the second trimester $[18,25]$. Obtaining a suitable transverse image is difficult in the third trimester. That is why the image quality did not meet our expectations in 44 of 162 pregnant women included in our study. In a study conducted by De Leon-Luis et al., concordance of $95 \%$ was observed for thymus circumference and thymus/thorax diameter. That measurement was not influenced by fetal sex [35]. Our study also revealed a positive correlation between thymus circumference and thymus/thorax diameter $(r=0.44, p<0.01)$. Therefore, we used the thymus diameter as the thymus size for subsequent statistical analysis.

Several important limitations apply to our study. First, the study group included a small sample of pregnant women and studies with a larger and more diverse study populations are necessary. Secondly, while we included mature neonates and we examined fetal thymic-thoracic ratio in our study, we did not investigate the association between fetal weight and fetal thymus measurements. Finally, the effect of different doses of vitamin D on thymic size was not evaluated. For future studies, we suggest that randomized controlled trials measure fetal thymic size during the second trimester in mothers receiving vitamin D replacement.

In conclusion, fetal VDD is a common occurrence worldwide. VDD during pregnancy can affect fetal programming of the thymus. Furthermore, these data suggest that vitamin $D$ deficiency during pregnancy may lead to systemic inflammatory response in the fetus. Thus, more research attention and patient awareness of the role of vitamin D in immune development is necessary. 


\section{Conflict of interests}

The authors declare that they have no conflict of interest.

\section{REFERENCES}

1. Cantorna MT. Vitamin $D$ and its role in immunology: multiple sclerosis, and inflammatory bowel disease. Prog Biophys Mol Biol. 2006, 92, 60-64.

2. Hayes $\mathrm{CE}$, Nashold FE, Spach KM, [et al.]. The immunological functions of the vitamin D endocrine system. Cell Mol Biol. 2003, 49, 277-300.

3. Güven A, Ecevit A, Sözer O, [et al.]. Correlation between the cord vitamin D levels and regulatory T cells in newborn infants. Eur J Pediatr. 2012, $171,1161-1166$

4. Prietl B, Treiber G, Pieber TR, [et al.]. Vitamin D and immune function. Nutrients. 2013, 5, 2502-2521.

5. Comberiati P, Tsabouri S, Piacentini GL, [et al.]. Is vitamin D deficiency correlated with childhood wheezing and asthma? Review. Front Biosci. 2014, 6, 31-39.

6. Morales E, Romieu I, Guerra S, [et al.].; INMA Project. Maternal vitamin D status in pregnancy and risk of lower respiratory tract infections, wheezing, and asthma in offspring. Epidemiology. 2012, 23, 64-71.

7. Disanto G, Watson CT, Meier UC, [et al.]. Month of Birth and Thymic Output FREE. JAMA Neurol. 2013, 70, 527-528.

8. Jacobsen $\mathrm{R}$, Abrahamsen $\mathrm{B}$, Bauerek $\mathrm{M}$, [et al.]. The influence of early exposure to vitamin $\mathrm{D}$ for development of diseases later in life. $B M C$ Public Health. 2013, 13, 515.

9. Mold JE, Venkatasubrahmanyam S, Burt TD, [et al.]. Fetal and adult hematopoietic stem cells give riseto distinct T cell lineages in humans. Science. 2010, 330, 1695-1699.

10. Koch U, Radtke F. Mechanisms of T cell development and trans-formation. Annu Rev Cell Dev Biol. 2011, 27, 539-562.

11. Pagenkemper $M$, Diemert A. Monitoring fetal immune development in humanpregnancies: current concepts and future goals. J Reprod Immunol. 2014, 104, 49-53.

12. Sakaguchi S. The origin of FOXP-3-expressing CD4+ regulatory Tcells: thymus or periphery. J Clin Invest. 2003, 112, 1310-1312.

13. Di Naro E, Cromi A, Ghezzi F, [et al.]. Fetal thymic involution: a sonographic marker of the fetal inflammatory response syndrome. Am J Obstet Gynecol. 2006, 194, 153-159.

14. Savino W, Dardenne M, Velloso LA, [et al.]. The thymus is a common target in malnutrition and infection. Br J Nutr. 2007, 98, S11-S16.

15. Palmer AC. Nutritionally mediated programming of the developingimmune system. Adv Nutr. 2011, 2, 377-395.

16. Aksakal SE, Kandemir O, Altınbas $\mathrm{S}$, [et al.]. Fetal tyhmus size as a pre dictor of histological chorioamnionitis in preterm premature rupture of membranes. J Matern Fetal Neonatal Med. 2014, 27, 1118-1122.

17. Yinon $Y$, Zalel $Y$, Weisz $B$, [et al.]. Fetal thymus size as a predictor of chorioamnionitis in women with preterm premature rupture of membranes. Ultrasound Obstet Gynecol. 2007, 29, 639-643.
18. Mohamed N, Eviston DP, Quinton AE, [et al.]. Smaller fetal thymuses in pre-eclampsia: a prospective cross-sectional study. Ultrasound Obstet Gynecol. 2011, 37, 410-415.

19. Harvey L, Burne TH, McGrath JJ, [et al.]. Developmental vitamin D3 deficiency induces alterations in immune organ morphology and function in adult offspring. J Steroid Biochem Mol Biol. 2010, 121, 239-242.

20. Yurdakök M, Haziroğlu R, Topaloğlu H. Fetal thymus development in vitamin D deficient rats. Turk J Pediatr. 1993, 35, 197-199.

21. Murr C, Pilz S, Grammer TB, [et al.]. Vitamin D deficiency parallels inflammation and immune activation, the Ludwigshafen Risk and Cardiovascular Health (LURIC) study. Clin Chem Lab Med. 2012, 50 (12), 2205-2212.

22. Coussens AK, Martineau AR, Wilkinson RJ. Anti-Inflammatory and Antimicrobial Actions of Vitamin D in Combating TB/HIV. Scientifica (Cairo). 2014, 2014, 903680.

23. Bobbitt KR, Peters RM, Li J, [et al.]. Early pregnancy vitamin D and patterns of antenatal inflammation in African-American women. J Reprod Immunol. 2015, 107, 52-58.

24. Liu NQ, Kaplan AT, Lagishetty V, [et al.]. Vitamin D and the regulation of placental inflammation. J Immunol. 2011, 186 (10), 5968-5974.

25. Eviston DP, Quinton AE, Benzie RJ, [et al.]. Impaired fetal thymic growth precedes clinical preeclampsia: a case-control study. J Reprod Immunol. 2012, 94 (2), 183-189.

26. Bodnar LM, Simhan HN, Catov JM, [et al.]. Maternal vitamin D status and the risk of mild and severe preeclampsia. Epidemiology. 2014, 25 (2), 207-214.

27. Robinson CJ, Wagner CL, Hollis BW, [et al.]. Association of maternal vitamin $\mathrm{D}$ and placenta growth factor with the diagnosis of early onset severe preeclampsia. Am J Perinatol. 2013, 30 (3), 167-172

28. Cetin O, Dokurel Cetin I, Uludag S, [et al.]. Serial ultrasonographic examination of the fetal thymus in the prediction of early neonatal sepsis in preterm premature rupture of membranes. Gynecol Obstet Invest. 2014, 78, 201-207.

29. Perampalam S, Ganda K, Chow KA, [et al.]. Vitamin D status and its predictive factors in pregnancy in 2 Australian populations. Aust NZJ Obstet Gynaecol. 2011, 51, 353-359.

30. Gür EB, Turan GA, Tatar S, [et al.]. The effect of place of residence and lifestyle on vitamin D deficiency in pregnancy: Comparison of eastern and western parts of Turkey. J Turk Ger Gynecol Assoc. 2014, 15, 149-155.

31. Halicioglu O, Aksit $S$, Koc F, [et al.]. Vitamin D deficiency in pregnant women and their neonates in spring time in western Turkey. Paediatr Perinat Epidemiol. 2012, 26, 53-60.

32. Hart PH, Lucas RM, Walsh JP, [et al.]. Vitamin D in fetal development findings from a birth cohort study. Pediatrics. 2015, 135 (1), e167-e173.

33. De Leon-Luis J, Ruiz Y, Gamez F, [et al.]. Comparison of measurements of the transverse diameter and perimeter of the fetal thymus obtained by magnetic resonance and ultrasound imaging. JMagn Reson Imaging. 2011, 33, 1100-1105.

34. Hasselbalch MB, Nielsen $D$, Jeppesen JF, [et al.]. Sonographic measurement of the thymus in infants. Eur Radiol. 1996, 6, 700-703.

35. De Leon-Luis J, Gámez F, Pintado P, [et al.]. Sonographic measurements of the thymus in male and female fetuses. JUltrasound Med. 2009, 28, 43-48. 